\title{
O PROGRAMA MAPA DO TURISMO BRASILEIRO E SUA ESPACIALIDADE NO MUNICÍPIO DE MARABÁ-PA
}

Hugo Rogério Hage Serra
Universidade Federal do Sul e do Sudeste do Pará, Laboratório de Estudos Regionais e Agrários do
Sul e do Sudeste do Pará, Marabá-PA, Brasil
serra@unifesspa.edu.br

Izabela Rodrigues Paz

Universidade Federal do Sul e do Sudeste do Pará, Laboratório de Estudos Regionais e Agrários do Sul e do Sudeste do Pará, Marabá-PA, Brasil izabelapaz@unifesspa.edu.br

\begin{abstract}
RESUMO
Este trabalho possui o objetivo de analisar a espacialidade do Programa Mapa do Turismo Brasileiro no município de Marabá por meio da regionalização do território paraense empreendida pelo governo federal. Parte-se de uma metodologia baseada na leitura dos documentos oficiais que possuem no traçado das políticas públicas de turismo no território brasileiro, por meio do Programa de Regionalização do Turismo. Empreende-se uma análise de conteúdo baseada na dedução e na inferência de fatos geográficos da referida política, entre as quais percebe-se uma tentativa de regionalizar o território a partir das diretrizes governamentais expostas na política de Estado. Os resultados mostram que agentes públicos e privados envolvidos no turismo de Marabá aderem ao PMTB apenas para angariarem fundos públicos, os quais, não necessariamente se manifestam em obras de repercussão espacial turística. Associado a isso, o PMTB toma o conceito de região turística como somatória de municípios sem haver um efeito regional entre eles.
\end{abstract}

Palavras-chave: Programa Mapa do Turismo Brasileiro. Turismo. Território. Região. Marabá.

\section{THE BRAZILIAN TOURISM MAP PROGRAM AND ITS SPATIALITY IN THE MUNICIPALITY OF MARABÁ}

\begin{abstract}
This work aims to analyze the spatiality of Brazilian Tourism Map Program (BTMP) in the municipality of Marabá through the regionalization of Pará territory undertaken by the federal government. It begins from a methodology based on official documents interpretation, which they are in the outline of public tourism policies in Brazilian territory, through the Regionalization Program for Tourism. The employed analysis is rooted on deduction and geographical facts inferences from the already referred policy, among which an attempt is made to regionalize the territory based on the government guidelines composed in the State policy. The results show that public and private agents involved in Marabá tourism adhere to the BTMP only to raise public funds, which do not necessarily have impact on tourist spatial repercussion. Associated to this, the BTMP takes the tourist region concept as the sum of municipalities without having a regional effect between them.
\end{abstract}

Keywords: Brazilian Tourism Map Program. Tourism. Territory. Region. Marabá.

\section{INTRODUÇÃO}

Não é recente o interesse estatal em difundir a atividade turística por todo território brasileiro. Vários esforços - desde a Era Vargas (CRUZ, 2001), por exemplo - vão ao encontro das políticas públicas, sendo estas últimas, uma forma de respaldar a ação do Estado no território "oficialmente". As tentativas de se implementar o turismo como mecanismo de desenvolvimento social nem sempre ecoam a contento do que se planeja, havendo, nitidamente, uma separação entre o espaço das concepções das coisas do espaço das coisas representadas. De todo modo, invariavelmente, as políticas públicas deixam uma geografia a ser analisada. Em cada contexto, há uma relação Estado- agentes do turismo - território que demarca a forma como o turismo é desenvolvido.

Não obstante a isso, desde 2003, quando o governo brasileiro assumiu a prerrogativa de delimitar o turismo em seu território por meio da região (BRASIL, 2003), todos os mecanismos de planejamento

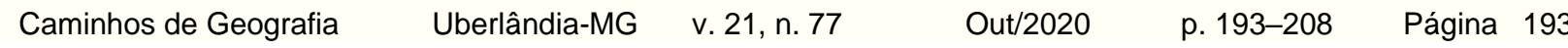


tiveram que se readaptar à nova estrutura de política pública. Um dos programas é intitulado "Programa Mapa do Turismo Brasileiro - PMTB" (BRASIL, 2019) - inserido no Programa de Regionalização do Turismo - PRT (BRASIL, 2013). A ideia central deste programa é "somar" o maior número de regiões turísticas a partir da incorporação de municípios interessados em ingressar no programa. No estado do Pará, o município de Marabá, localizado no Sudeste de seu território, torna-se um dos municípios participantes do PMTB. Por meio deste Programa, Marabá tenta ser incorporado como município que trata o turismo como uma "questão de Estado", reservadas suas devidas diferenças escalares.

Este trabalho é parte de um projeto de pesquisa que investiga a relação entre a política de turismo do governo federal e o papel dos agentes públicos de turismo no município de Marabá - PA. Considerase o PMTB como objeto central da pesquisa. Neste sentido, parte-se de um questionamento central: como se dá a espacialização do PMTB no município de Marabá? Seu objetivo principal reside em analisar a espacialidade do PMTB no município de Marabá por meio da regionalização do território paraense empreendida pelo governo federal. A análise se dá considerando a importância que os documentos oficiais possuem no traçado das políticas públicas de turismo no território brasileiro. Empreende-se uma análise de conteúdo baseada na dedução e na inferência conforme Bardin (1977), mas que está cercada por um olhar regional-geográfico no território de Marabá em relação ao território nacional, a partir das determinações políticas dos agentes envolvidos no processo de composição da política pública de turismo.

A fim de melhor organizar o mecanismo das ideias até aqui expostas, procede-se a uma divisão na qual, em um primeiro momento, discute-se, brevemente, a política pública como elemento de ponto de partida conceitual. A base conceitual, nestes termos, está centrada na ideia de Steinberger (2013, 2017), em que se afirma haver uma tríade entre o Estado, as políticas públicas e o território. Na segunda parte do texto, retoma-se o PMTB para se mostrar as diretrizes, os pontos centrais do programa e a divisão pela qual o governo federal convencionou chamar de mapa. $\mathrm{Na}$ última etapa do trabalho, mostra-se os resultados da pesquisa. Neste momento, centra-se a análise, principalmente, nos sujeitos envolvidos no processo de espacialização do PMTB em Marabá, suas ideias e as repercussões geográficas.

\section{AS POLÍTICAS PÚBLICAS, O TERRITÓRIO E O ESTADO: BASES GERAIS PARA A COMPREENSÃO DO PROGRAMA MAPA DO TURISMO BRASILEIRO}

Ainda que haja uma intenção e uma ação pragmática do governo federal em desenvolver a contento o PMTB, a relação com as diretrizes das políticas públicas que tornam o referido programa uma realidade são um fato. Dito de outra forma, os programas federais espelham políticas, sejam elas esclarecidas ou não; estejam dentro de um escopo político-social e econômico bem definido ou que estejam, apenas, inseridas em uma determinada ocasião histórica na qual o Estado se encontra. De antemão, o fato reside na associação inequívoca entre as políticas públicas e os programas de governo, bem como, de forma mais ampla, na necessidade de um conjunto de pessoas tomarem decisões de forma organizada.

Melazzo (2010) inicia o debate sobre as políticas públicas distinguindo-as entre o campo conceitual e o campo operacional. Segundo este autor, do ponto de vista da economia, a tomada de decisão sobre recursos econômicos (e aí, incluem-se as finanças) é a perspectiva assumida por aqueles que partem desse princípio; no campo sociológico e das ciências políticas, interessa saber qual o resultado da interação entre os agentes através da política. Por fim, segundo ainda o autor, para os que partem da administração pública, o Estado toma lugar central no debate das políticas, o que envolve um determinado contexto, uma estrutura normativa (que imponha normas a uma dada coletividade) e uma intervenção.

Não menos diferente do que aponta Melazzo (2010), pode-se dizer que um aspecto geográfico também está presente no debate conceitual sobre as políticas públicas. Desta feita, a geografia aludida aqui não se sobrepõe às demais dimensões anteriormente expostas. Junto a isso, o aspecto geográfico contido nas políticas públicas pode ser encarado como algo transversal, pois, em qualquer hipótese, uma decisão econômica, o resultado da interação dos agentes, bem como a tomada de decisões de um Estado por meio de um conjunto normativo, invariavelmente, partem de uma dada estrutura espacial, se desenvolvem nela e resultam em uma possível nova realidade espacial, podendo estar ressignificada ou, apenas, acrescentada de elementos sociais diferentes da realidade original.

De forma mais direta e objetiva, as políticas públicas são a forma pela qual os agentes envolvidos afetam, interferem e implicam em decisões que, por seu turno, modificam a vida de muitos, mesmo que 
haja um bom contingente populacional que não tenha concordado com as decisões dos principais agentes da política pública, entre eles (e, principalmente ele, o Estado em seus diferentes níveis escalares). Ao se partir da noção de totalidade espacial da qual nos reserva Santos (2005), por exemplo, nota-se que as contradições espaciais, expressas em diferentes proposições políticas projetadas no espaço (bem como a partir dele), abarcam as diferenças de opiniões e ensejos, daí, portanto, haver clareza de que toda política pública, além de não agradar a todos, também não proporciona alcance a todos.

As contradições vividas pelo Estado - principal agente da política pública - são notadas por Dias e Matos (2012) quando dizem que um de seus principais desafios está em recuperar prerrogativas no campo da economia, política, cultura e sociedade. Algo que, segundo esses autores, o Estado tem enfrentado com dificuldade em um contexto de globalização. Para eles:

Os novos espaços de articulação global, tanto políticos como econômicos - de que são exemplos os blocos comerciais -, tendem a modificar a execução das políticas públicas no âmbito do território do Estado. A interdependência crescente dos Estados abrange não só os aspectos de execução de suas políticas, mas até mesmo as práticas sociais e culturais de suas respectivas sociedades (...) (DIAS e MATOS, 2012, p. 25).

De forma diferente, porém complementar, Secchi (2013) afirma haver três nós conceituais para política pública. O primeiro nó encerra uma disputa entre um grupo mais 'estadocêntrico' (state-centered policy making) e outro grupo que defende uma abordagem 'multicêntrica'. Este último busca a compreensão da política pública a partir de personagens não-estatais, tais como as ONGs e os movimentos sociais.

A abordagem centrada no Estado considera o Estado como agente legítimo e exclusivo na elaboração, formulação de agenda, implementação e avaliação da política pública, segundo Secchi (2013). Por este prisma, compreende-se que o Estado é superior no tocante às leis e a sociedade deve cumprir o que se origina do Estado. Quando há distorções, é o Estado o agente responsável por corrigir falhas, como as do Mercado, por exemplo.

De outra forma, a abordagem intitulada como multicêntrica parte da composição de uma rede de políticas públicas (policy networks). Nesta perspectiva, a diversidade de agentes que fazem parte da arena política, com seus territórios demarcados por objetivos específicos na luta por espaço, assim como pela demarcação nas políticas públicas, torna-se o mote central. Secchi (2013) ainda complementa:

(...) Em geral, as políticas públicas são elaboradas dentro do aparato institucionallegal do Estado, embora as iniciativas e decisões tenham diversas origens. (...) Estado e sociedade se articulam em esquemas espontâneos e horizontais para a solução de problemas públicos (SECCHI, 2013, p. 3, grifos do autor).

O segundo nó conceitual apresentado por Secchi (2013) refere-se à inação pública diante de problemas sociais. Nessa perspectiva, a omissão do governo passa a ser encarada como um ato de política pública, ideia esta evitada por Secchi (2013), pois segundo ele, o ato de não fazer política pública dever ser compreendido como um instante do planejamento não considerado na agenda formal, algo que não pode ser confundido com inação do poder público.

Por fim, o terceiro nó conceitual apresentado por Secchi (2013) se relaciona ao poder estruturante que uma política pública possui. Por esse critério, então: "programas, planos e projetos são apenas elementos operativos, não podendo ser considerados políticas públicas individualmente" (SECCHI, 2013 , p. 7). O grande problema dessa prerrogativa, na prática, tem a ver com a não percepção de outras políticas públicas de diferentes escalas de atuação do Estado, tais como a estadual, a municipal ou, até mesmo, no entrecruzamento de demandas de diferentes sujeitos em diferentes níveis espaciais. O mesmo autor se posiciona firmemente quanto a esta abordagem:

Nosso posicionamento é de que as políticas públicas são tanto as diretrizes estruturantes (de nível estratégico) como as diretrizes de nível intermediário e operacional. Aliás, grande parte da construção teórica dos policy studies acontece sobre a análise de programas, planos e políticas públicas locais ou regionais (SECCHI, 2013, p. 7).

Eis que, novamente, Melazzo (2010) aponta para diferentes dimensões que envolvem as decisões do Estado, o que implica em conteúdos particulares das políticas públicas. Esses elementos levam às 
indagações de quem as formula e qual a destinação delas. Nesse ponto, evocar a dimensão espacial contida nos desejos de quem faz parte do jogo é algo inerente às políticas públicas, algo, nesses termos, relacionado à realidade a ser transformada (MELAZZO, 2010).

Steinberger (2013) é uma autora que não desassocia suas explicações de políticas públicas do Estado e do território, o que implica em uma tríade. Para essa autora, de forma inicial, ainda que não haja uma abordagem explícita do Estado em reconhecer uma legítima dimensão espacial nas políticas públicas por meio da categoria território, não há como dissociar uma coisa da outra. Em maior ou menor grau de apropriação e intervenção estatal, as políticas públicas estão vinculadas ao território. Ainda assim, Steinberger (2013) alerta para a necessidade de se levar em conta os discursos dos agentes políticos envolvidos emaranhados em contextos "e trajetórias, nas quais as políticas foram e são concebidas" (STEINBERGER, 2013, p. 23).

Ao se apropriar, ainda, das ideias de Steiberger (2013), especificamente, aquelas delimitadas no contexto histórico brasileiro pós-segunda guerra mundial, concorda-se com a autora quando ela afirma que há três períodos que se separam no tempo, mas que possuem forte relação com as demandas oriundas da pressão do modo de produção no território, o que implica em manifestações políticas díspares.

O primeiro contexto das políticas apontadas por Steinberger (2013) revela um 'Estado concentrador e empresário', iniciado nos anos 1950 e que se estendeu até o final de 1980. A forte presença do Estado concentrador e centralizador de políticas públicas é a marca desse período. Por meio da difusão do papel de Estado- Empresário de bens de capital, o território brasileiro era "preenchido" por um amplo sistema de engenharia, facilitador da iniciativa privada. Outra característica marcante é a dimensão do 'Estado do bem-estar social' que, segundo aquela autora era "obediente a um modelo de crescimento autárquico e exógeno, mas de políticas compensatórias dos seus efeitos, entre as quais ambiental, a regional, a urbana e a rural que visam arrefecer e, até mesmo, ocultar conflitos (STEINBERGER, 2013, p. 24).

O segundo contexto identificado por Steinberger (2013) é o neoliberalismo. No Brasil, a década compreendida entre os anos 1990 e 2000 foi o momento de maior difusão dessas ideias. Estado mínimo, Estado-regulador e terceirização são características essenciais para a compreensão desse momento para a política nacional. No entanto, segundo a autora, flagrantemente, neste período houve "uma ausência de planejamento nacional e de formulação de políticas públicas, substituída por uma administração pontual via projetos e programas (...) (STEINBERGER, 2013, p. 24).

Este momento resultou em uma plêiade de situações-problema que, de certa forma, pode-se dizer que fizeram retroagir no entendimento da participação da sociedade civil. Os Movimentos Sociais e a presença de Organizações Não-Governamentais (ONGs) eram tidos como sujeitos que substituíram o Estado Nacional. O processo de descentralização, segundo Steinberger (2013) - previsto na Carta Magna de 1988 - era, também, confundido com a negativa da centralização do Estado em assuntos cruciais na organização da sociedade brasileira.

O terceiro e último momento discutido por Steinberger (2013) é intitulado 'Estado-híbrido' e iniciou-se em 2003. Por ser híbrido, há que se perceber uma não-superação dos modelos de Estado anteriores a esse contexto; por sua vez, uma associação do antigo com o novo, torna-se uma marca para este momento. Para a autora, dentre as principais ações estão a ampliação do quadro da máquina do Estado ou, de outra forma, um reaparelhamento do Estado, bem como um retorno do planejamento para o território, mas com uma presença mais atuante de segmentos sociais que nunca tiveram acesso à agenda do planejamento como um todo. É nesse momento que a dimensão territorial ganha força no processo de elaboração, planejamento e avaliação das políticas públicas, caracterizada por ampla participação da sociedade. Porém, não se deve deixar de mencionar que o capital financeiro - já muito atuante à época - não deixava de fazer parte do núcleo de decisões do governo, daí uma das marcas expressivas do Estado-híbrido.

À obra de Steinbeger (2013) pode-se atualizar o contexto pelo qual as políticas públicas passam na atualidade. O rechaço ao Estado como figura de antítese à dinâmica de desenvolvimento social é a marca expressiva neste contexto. Já não se trata mais de hibridismo do Estado, muito menos um Estado centralizador. Por outro lado, a profunda imersão do capital financeiro nas decisões governamentais - associadas a uma tentativa apressada e desarrazoada de internacionalização das riquezas naturais, tais como o petróleo do pré-sal levam a um contexto intitulado 'desmonte do Estado'. 
Para Cardoso Jr. (2019), há uma clara diferença entre o início deste século e término desta década no que confere à governabilidade política brasileira, vista a partir do aparelhamento do Estado. Para ele, havia um reforço na reflexão, formulação e comunicação para implementar estratégias de governo. Tal situação garantiria a governabilidade do país, bem como estimularia a governança interna entre os órgãos. A partir de 2019, para aquele autor, mudanças como rebaixamento institucional, articulação política por meio de órgão participativos e, por outro lado, centralização do planejamento no Ministério da Economia são marcas expressivas do atual momento por qual passa o país.

Se entre os anos 2003 e 2016 a presença da categoria território era notória entre as formas de se pensar o planejamento para as políticas públicas, a partir desse último ano, começa a haver uma reconfiguração ou, até mesmo, uma descompatibilização entre as políticas públicas, no sentido mais espacial ou - em que pese esse conceito - uma diretriz política. Nesse sentido, ainda que Steinberger (2013) afirme que as políticas públicas não sejam uma prerrogativa apenas do Estado, percebe-se o quanto este agente se torna - com certa dinâmica e fluidez política - centralizador em suas decisões. A mesma autora, porém, em trabalho mais recente, reconhece a significativa perda de importância do território a partir de 2017, quando o governo brasileiro deslegitima o território como base norteadora na formulação e implementação de políticas públicas (STEINBERGER, 2017).

Para Randolph (2017), há uma dicotomia, uma separação entre a estrutura (nutrida pelo Estado) e os agentes (pluralidade de extratos sociais, organizados socialmente). Isso se torna mais palatável de ser compreendido quando se analisa o papel dos grupos sociais diretamente vinculados às políticas públicas.

A esse propósito, Faria, Karam e Santos (2017) analisam o conceito de 'agente-ator' dentro das políticas públicas. Ainda que haja uma associação não muito clara entre as duas categorias (especificamente no que se refere à definição de agente e de ator político), para os autores, cada um tem um papel fundamental no processo de concepção, implementação e avaliação da política pública, algo que faz repensar constantemente a 'agenda' política.

A divisão entre agentes internos e externos à estrutura do Estado é necessária na configuração da função de cada um dos sujeitos. Trata-se, nesses termos, de uma relação representatividaderepresentado, o que perfaz um caminho mediado pelas relações de poder na composição das políticas. Ao citar Kingdon, Faria, Karam e Santos (2017) afirmam que há três grupos pertencentes ao jogo político, quais sejam: a) administração pública; b) burocratas e servidores públicos de carreira e c) agentes-atores vinculados ao poder legislativo.

O primeiro grupo citado por Faria, Karam e Santos (2017) tem o presidente como figura central da política. É nesse grupo - core area - da administração pública que o poder de influência sobre as políticas desenvolve-se de forma mais incisiva, porém não de forma homogênea, pois o presidente sozinho - não consegue definir políticas a fim de implementá-las. Junto ao poder do presidente, o staff da administração presidencial (equipe presidencial) tem o poder de influenciar na decisão do presidente, daí haver uma relação inequívoca entre os dois atores sociais. Essa relação ainda é complementada por atores do segundo escalão da equipe presidencial, os quais, atuam de forma mais dinâmica em fóruns de debates sobre as políticas públicas.

O segundo grupo abordado por Faria, Karam e Santos (2017) centra-se nas figuras dos burocratas e servidores públicos de carreira. Por serem sujeitos que atuam na administração pública há muito tempo (ou, ao menos, lidam com as questões burocráticas cotidianamente) conseguem proceder a uma leitura técnica (às vezes tecnicista) dos elementos norteadores da 'agenda': "esse grupo dispõe de um conjunto de recursos materiais e financeiros, o que lhes assegura grande influência na produção de Políticas Públicas Espaciais (FARIA, KARAM E SANTOS, 2017, p. 104, grifos dos autores).

O terceiro grupo, segundo Faria, Karam e Santos (2017), é especificado pelo poder legislativo, o qual Ihe é conferido, cada vez mais, influência na decisão das aprovações das políticas. Pode-se dizer que deste grupo emanam importantes manobras na configuração final as políticas. Isso se deve, em tese, à funcionalidade a qual eles estão vinculados, ou seja, eles são os fiscalizadores da lei e, por este motivo, o contato direto com as questões políticas passa a ser uma espécie de 'hábito'. Deve-se deixar claro que não se trata de uma visão fechada sobre o poder legislativo, como se todos tivessem habilidades ou uma expertise. Contudo, é inegável a transitabilidade das questões decisivas da sociedade no que confere à agenda das políticas públicas. 
Por fim, porém não menos importante, os agentes-atores "externos à estrutura do Estado" (FARIA, KARAM E SANTOS, 2017, p. 105). O que mais caracteriza esse grupo é o interesse em conhecer a estrutura interna do sistema da política pública que, do ponto de vista técnico, fica a cargo dos anteriormente já citados. Pelo fato de representarem seus lugares e regiões, pode-se dizer que eles não fogem à produção das políticas públicas espaciais. Atuam nas brechas deixadas pelos agentes internos e, por meio da pressão, atuam como difusores de informações junto à sociedade civil como um todo, o que pode fazer com que haja uma reconfiguração na opinião pública. Segundo Faria, Karam e Santos (2017), esses agentes-externos são: os pesquisadores, os acadêmicos, mídia, partidos políticos e a população organizada em diversos grupos de interesse.

As políticas públicas não ecoam ou não se materializam se não houver o que Brandão (2014), por exemplo, afirma ser uma consolidação de acumulação potente de forças sociais e políticas a fim de superar problemas sociais. Neste sentido, uma análise das políticas públicas em que não pese uma articulação entre as bases sociais e os sistemas de representação política produz uma miríade de políticas de governo e não políticas de Estado, ou, como dizem Klink, Oliveira e Zimerman (2014) há uma desconexão efetiva de projetos com as bases. Ao retomar o pensamento de Brandão (2014), pode-se entender que a divisão analítica feita por Faria, Karam e Santos (2017) de nada vale se não houver uma expressividade das contradições sociais. Não sem menos:

\begin{abstract}
Examinar a organização espacial como manifestação e expressão contraditória das relações sociais de produção e das lutas sociais, lançando um olhar sobre os conflitos que se encadeiam e tecem o ambiente construído socialmente não é tarefa fácil e na maioria das vezes é muito mais conveniente e simples escolher no "menu teórico" a cópia de algum modelo analítico abstrato, aplicando-o a determinada "realidade" urbano-regional (...) (BRANDÃO, 2014, p. 132, sic, grifos do autor).
\end{abstract}

A chamada feita por Brandão (2014) no parágrafo anterior mostra que a divisão de funções entre os agentes-atores, tal como mostrado a partir do trabalho de Faria, Karam e Santos (2017), é infrutífera se não houver uma autêntica coesão política, seja em qual escala as ações se dão (algo que pode, até mesmo, ocorrer entre as escalas, por meio da transversalidade). Reconhece-se que há uma obscuridade neoliberal (FERNÁNDEZ, 2014) que empata a relação intrínseca pretendida entre os agentes. Contudo, percebe-se que as forças isoladas não produzem uma política pública menos desigual.

O caminho traçado até aqui permite que se vislumbre como uma política pública, tal como o Programa Mapa do Turismo Brasileiro - PMTB, possa ser analisado e compreendido, principalmente, a partir de pontos cruciais que permitem a interpretação das ideias, bem como do jogo político que envolve as relações de poder concernentes às decisões do governo brasileiro. Inevitavelmente, a elaboração de um programa como esse reflete uma espacialidade oriunda de interesses dos agentes da política pública, responsáveis pela concepção estatal da atividade turística. O PMTB é contido por uma diretriz específica de turismo, bem como de política que, direta ou indiretamente, reproduz uma geografia regional a fim de fazer valer a presença do Estado nas diferentes regiões do território brasileiro, o que faz do turismo uma política territorializada por meio de agentes-atores do ramo.

\title{
O PROGRAMA MAPA DO TURISMO BRASILEIRO E AS ESTRATÉGIAS REGIONAIS DE AFIRMAÇÃO DO TURISMO NO TERRITÓRIO NACIONAL
}

O PMTB é fruto de uma tentativa do governo federal brasileiro de alcançar uma política nacional de turismo em todo o território nacional por meio da instrumentalização das regiões brasileiras, as quais devem seguir a uma ampla descentralização da gestão, estruturação e promoção do turismo, conforme o que rege o Programa Nacional de Turismo, de acordo com a portaria n. 105, de 16 de maio de 2013 (BRASIL, 2013). A portaria em questão está atrelada a um dispositivo político maior que é a Política Nacional de Regionalização do Turismo, conforme a Lei n. 11.771, de 17 de setembro de 2008.

A ideia referente à descentralização anunciada no Programa faz com que o governo federal estimule estados e municípios a promoverem 'ações orientadoras' para o turismo a partir da adesão ao que o governo intitula ser o 'mapa'. Neste sentido, cabe às instâncias dos estados (por meio de fóruns 
regionais de turismo) e dos municípios (por meio de órgãos que tratem do tema turismo de forma direta e indireta) articularem seus interesses a fim de desenvolver um fluxo de atividades turísticas de quaisquer ordens, para que haja uma espécie de conformação do mapa, tal como se propõe na própria portaria aludida anteriormente por meio da figura 1:

Figura 1 - Níveis de atuação referentes ao Programa de Regionalização do Turismo - 2013.

\begin{tabular}{|l|l|l|c|}
\hline \multicolumn{5}{|c|}{ Gestão Compartilhada do Programa de Regionalização do Turismo } \\
\hline ÂMBITO & \multicolumn{1}{|c|}{ INSTITUIÇÃO } & \multicolumn{1}{c|}{ COLEGIADO } & EXECUTIVO \\
\hline Nacional & \multicolumn{1}{|c|}{ Ministério do Turismo } & Conselho Nacional & Comitê Executivo \\
\hline Estadual & Órgão Oficial de Turismo da UF & $\begin{array}{l}\text { Conselho / Fórum } \\
\text { Estadual }\end{array}$ & Interlocutor Estadual \\
\hline Regional & \multicolumn{1}{|c|}{ Instância de Governança Regional } & Interlocutor Regional \\
\hline Municipal & $\begin{array}{l}\text { Órgão Oficial de Turismo do do } \\
\text { Município }\end{array}$ & $\begin{array}{l}\text { Conselho / Fórum } \\
\text { Municipal }\end{array}$ & Interlocutor Municipal \\
\hline
\end{tabular}

A organização apresentada na figura 1 apresenta uma tentativa de conectar o território brasileiro a partir do peso que o dispositivo legal emitido pelo governo federal possui. O PMTB possui um poder de difundir as prerrogativas da lei a partir do esforço dos agentes-atores envolvidos no processo. Tais agentes - os que decidiram sobre as regras - encontram-se como representantes do executivo e exercem um comportamento nos moldes da tecnoburocracia (SOUZA, 2001), sem a ampla participação de diferentes agentes regionais ligados ao turismo.

Por outro lado, o mecanismo de entrada dos municípios interessados em fazer parte do 'Mapa' é feito pela criterização instituída pela portaria no 313 , de 3 de dezembro de 2013. Tal normativa é que dispõe das características centrais do referido programa:

Art. 2o: Na definição de cada região turística integrante do Mapa do Turismo Brasileiro, instituído pela portaria MTur no 313, de 03 de dezembro de 2013, deverão ser observados os seguintes critérios: I- os municípios devem possuir características similares e/ou complementares e aspectos que o identifiquem enquanto região, ou seja, tenham uma identidade histórica, cultural, econômica e/ou geográfica em comum; II- os municípios devem ser limítrofes e/ou próximos uns aos outros; III- a Região Turística deve apresentar comprovação de ciência do Fórum ou do Conselho Estadual de Turismo acerca de sua composição.

Art. 3: Para integrar uma região turística do Mapa do Turismo Brasileiro, cada município deverá atender aos seguintes critérios: I - possuir órgão responsável pela pasta de turismo (Secretaria, Fundação, Coordenadoria, Departamento, Diretoria, Setor ou Gerência); II - comprovar a existência de dotação para o turismo na lei orçamentária anual vigente; III - apresentar Termo de Compromisso assinado por Prefeito Municipal ou dirigente responsável pela pasta de turismo, conforme modelo disponibilizado, aderindo de forma espontânea e formal ao Programa de Regionalização do Turismo e à Região Turística.

Art. 4: O Mapa do Turismo Brasileiro deverá ser periodicamente atualizado pelo Ministério do Turismo (BRASIL, 2013, p.1).

O 'passo-a-passo' ou escrutínio a ser feito na portaria que institui o 'Mapa' leva a uma análise regional que permeia ora as ideias de região-funcional ora a região pela integração. O dispositivo legal afirma que só há a região turística quando a proximidade espacial entre os municípios houver. Ainda que a ideia de similaridade ou coerência histórica entre os recortes espaciais exista, pelo processo de criterização oficial do governo, o 'mapa' só tem sentido como política pública se a contiguidade territorial na escala local for materializada. Hipoteticamente, esse recurso legal acaba se tornando uma espécie 
de gatilho contingenciador no território, regulando, nesses termos, a região em todos os seus aspectos. Haesbaert (2010), por exemplo, afirma que o caráter regional se vale muito mais pelas congruências regionais mediadas pelos processos econômicos, sociais e culturais entre os fragmentos espaciais que pleiteiam uma configuração regional do que pela força das normas. O autor deixa claro, porém, que a dimensão econômica se torna o carro-chefe em muitas regionalizações feitas, o que redefine (podendo até mesmo anular) a proximidade territorial, tal como se visualiza na escala local. Nesse sentido, uma rede regional é mais factível, independentemente de sua proximidade espacial, algo não vislumbrado no processo de criterização do PMTB.

Os critérios vinculados à portaria supracitada são condicionantes para a captação de recursos públicos. Para tanto, a configuração de fóruns regionais, bem como de órgãos locais destinados ao fomento, elaboração e efetividade do turismo são outros elementos obrigatórios. Sem a presença deles, o PMTB não consegue ser atualizado anualmente, o que, na prática, torna-se mais um dispositivo dos critérios do programa.

Outro fato importante a ser mensurado diz respeito à mudança de escala de atuação da política nacional de turismo, que mantém seu formato desde 2003, quando se elegeu a região como principal recorte analítico e exequível de toda política pública territorial para a atividade turística. Anteriormente, o processo de difusão do turismo caracterizado pelo governo federal baseava-se nos processos endógenos dos municípios, aqueles interessados em desenvolver uma atividade turística como uma dimensão de governo e como algo necessário para o desenvolvimento local. Àquela época, o Programa Nacional de Municipalização do Turismo - PNMT (BRASIL, 1997) era o principal documento norteador do turismo, conjuntamente com o Programa Nacional de Ecoturismo para a Amazônia Legal - Proecotur (BRASIL, 1998).

Ainda no que se refere à portaria no 313, de 3 de dezembro de 2013 (BRASIL, 2013), há que se destacar o peso burocrático necessário à efetivação do PMTB. A presença de um Fórum em instância regional, bem como de um órgão de turismo (ou que ao menos possua o turismo como um dos componentes) faz diferença na composição representativa de seus participantes, bem como dos lugares que eles representam.

Essa discussão tem a ver, em grande medida, com as ideias que Souza (2001) trata quando lida com a problematização do planejamento e da gestão, os quais são infrutíferos se estiverem imersos na esfera da tecnocracia. Em outros termos, o peso técnico - típico de discursos políticos de dimensões político-administrativas - não pode ser maior do que o movimento da realidade, sobretudo a partir de uma articulação democrática entre os diferentes representantes de um segmento social (neste caso, em específico, o turismo). A tecnocracia, além de sobrepor o 'tecnicismo' (com o excesso da burocracia) aos diversos discursos de sujeitos invisibilizados na trama política, não permite com que haja o exercício pleno da democracia (até mesmo de forma mais pedagógica possível), na qual a contradição é garantida. Como forma de ratificar seu pensamento, Souza (2001) é firme em seu discurso:

\begin{abstract}
(...) Pode-se aqui, aliás, arriscar uma hipótese: se a prática política em um contexto heterônomo costuma converter os planejadores, sejam funcionários do Estado ou a serviço do capital privado, em sofistas dedicados a impressionar o público com seus planos, sua maquetes e suas projeções, um contexto administrativo um pouco mais autônomo, que garanta um mínimo de transparência e accountability, pode justamente assegurar que os planejadores terão mais liberdade, também eles, para não se deixarem degradar ao papel de técnicos dispostos a defender acriticamente os interesses dos poderosos (SOUZA, 2001, p. 99).
\end{abstract}

Em uma atividade como a da formulação das políticas públicas de turismo, a assertiva de Souza (2001) acaba por servir como um autêntico alerta na tomada de decisão pelos agentes políticos, em suas diferentes escalas espaciais. Não sem menos, ao se reportar à normativa federal do PMTB, os critérios de composição dos fóruns regionais do turismo, bem como dos órgãos locais (ver novamente figura 1), podem não contemplar uma diversidade de sujeitos que praticam a atividade turística na condição de grupos vinculados a um tipo de circuito inferior da economia. Aqui, toma-se emprestada - ainda que de forma grosseira - a ideia defendida por Santos (2004) quando este autor defende um raciocínio

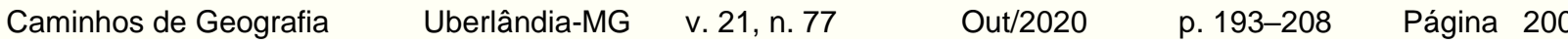


paradoxal no modo de produção capitalista para se entender a divisão entre ricos e pobres no planeta, mantida por uma complementariedade desigual entre eles.

Nestes termos, quando se exige a necessidade de um Fórum e de um órgão local, corre-se o risco de criar mecanismos pouco efetivos para as decisões que envolvem uma ampla participação de agentesatores do turismo nos diferentes municípios brasileiros. Esta prerrogativa ainda é mais distinta entre as macrorregiões brasileiras, ou, dito de outra forma, entre as regiões que possuem apelo turístico mais bem consolidado e as que não possuem. Neste ínterim, os municípios da região Norte do Brasil produzem uma menor fluidez no que se refere ao trânsito das ideias, bem como às implementações da política oriunda do PMTB.

Não se deve fazer apanágio a um determinismo geográfico. Contundo, as distâncias geográficas entre municípios de estados como Amazonas, Pará e Amapá, por exemplo, dificultam, em muito, o sentido de proximidade territorial exigido pelo critério do PMTB, algo que poderia ser mitigado pelas relações espaciais, ou, mais propriamente, pelas afinidades contidas nos espaços relativos e nos espaços relacionais ditados por Harvey (2012).

Para Harvey (2012), ao se deparar com os fenômenos espaciais de forma mais detida (e aqui, sem embargos, a política de turismo é fruto de uma concepção territorial inscrita sob o recorte das regiões), pode-se entender o grau de complexidade da natureza dos processos que envolvem pessoas e coisas, objetos e ações. Por seu turno, se o espaço é visto de maneira absoluta, as ideias planejadas são emolduradas naquilo que as constitui; logo, o trânsito é livre para as ideias, sem obstáculos ou acasos. Adiante, caso o espaço seja encarado de forma relativa, as decisões sobre a realidade dependem daquilo que se propõe e do lugar de onde elas partem. O espaço relacional, por sua vez, depende do processo social: "O conceito de espaço está embutido ou está interno ao processo" (HARVEY, 2012, p. 12).

Ao se tomar a análise de Harvey (2012) e ao correlacioná-la às normas vigentes no PMTB, em especial para a região Norte do Brasil, vê-se que há uma predisposição ao espaço absoluto como dimensão central na tomada de decisão sobre os critérios de constituição do 'Mapa'. Essa visão interpretativa não se torna mero discurso visto que as particularidades geográficas das regiões não permitem uma completude dos termos oficiais, o que acaba gerando incongruências, tais como a que se percebe na relação do município de Marabá com as diretrizes do PMTB.

\section{O PROGRAMA MAPA DO TURISMO BRASILEIRO E SUA ESPACIALIDADE NO MUNCÍPIO DE MARABÁ: ESCALAS, PROCESSOS, AGENTES-ATORES E AS INCONGRUÊNCIAS REGIONAIS}

O PMTB é adotado em Marabá e tem este município como central nas discussões concernentes ao programa. Historicamente, Marabá já concentrara esforços na condição de núcleo urbano que influenciava localidades em sua hinterlândia, o que já apontava, desde sua gênese, para uma potencial interferência nos fluxos de pessoas, mercadorias e ideias, sua localização no encontro entre os rios Itacaiúnas e Tocantins tornou-se trunfo para diversos mercadistas da região ligados à exploração de recursos naturais que abasteciam mercados regionais e, principalmente, estrangeiros. Exemplos notáveis como: a) exploração do caucho (em substituição à borracha, mais localizada nas porções central e setentrional do estado); b) exploração da castanha (a que deixara marcas profundas na da região em todos os segmentos sociais e econômicos) fizeram de Marabá uma cidade de destaque regional em um pouco mais de 100 anos.

A urbanização de Marabá e seus efeitos espaciais provenientes dessa condição geográfica na Amazônia produzem uma hierarquia urbano-regional importante para se compreender fenômenos de ordem regional em diferentes frentes socais. Para situações concernentes às políticas de turismo, Marabá centraliza o debate até mesmo por conter uma série de serviços e infraestrutura mínimos para o desenvolvimento da atividade. É uma cidade central em meio a uma região onde os fluxos de pessoas, mercadorias e ideias passam por ela.

A figura 2, a princípio, mostra a disposição cartográfica na qual Marabá torna-se referência espacial, bem como sua relação com vários municípios através de uma política regional adotada pelo governo 
do estado do Pará para a relação política-turismo. Ainda no que se refere a essa figura, notam-se os municípios de: a) Parauapebas, onde a exportação de minério tornou-se uma das vertentes paradigmáticas da economia não só do Pará, mas do Brasil; b) Conceião do Araguaia, cidade da porção meridional do Pará fundada por Jesuítas e que pertence a uma formação histórico-regional distinta de Marabá, assim como distinta de Belém, localizada bem mais ao norte. Ambas, integram as concepções regionais norteadores para as políticas de turismo:

Figura 2 - Mapa da Região Araguaia-Tocantins e Região-polo Belém com Marabá em destaque, 2017.

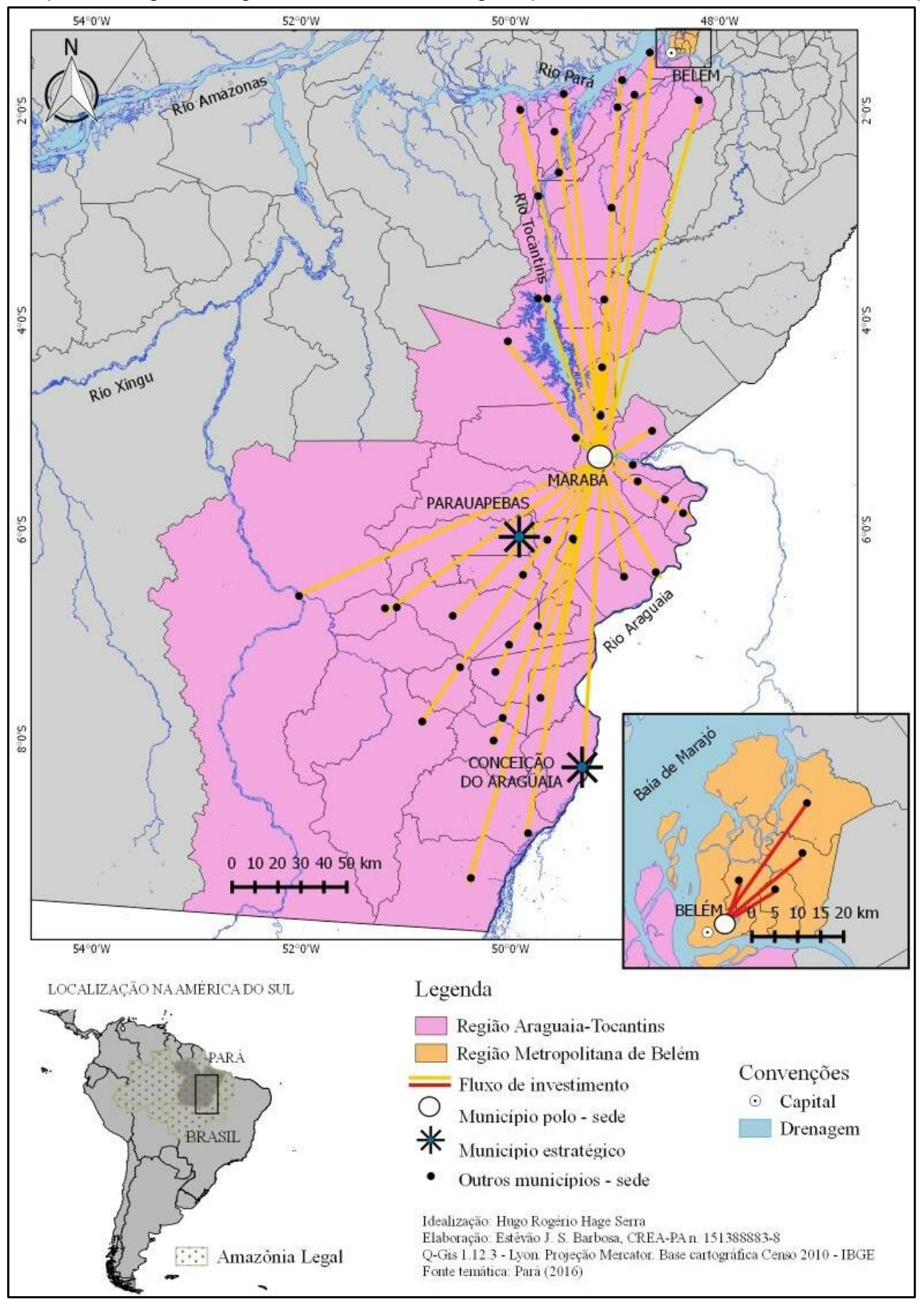

Fonte - Pará (2016).

Uma das questões tácitas no PMTB é a centralização do debate acerca do desenvolvimento do 'Mapa' por meio de forças políticas decisivas no processo de implementação da política do governo. É nesse contexto que Marabá, por meio de seu aparato institucional, sobressai-se em relação ao demais municípios. Com a presença de um órgão local da prefeitura onde as discussões políticas sobre a atividade turística se dão de forma mais atuante (Secretaria Municipal de Turismo de Marabá), bem como de um Conselho Municipal de Turismo (Comtur-Marabá), a política de turismo se concentra nesta 
cidade, principalmente, a partir do jogo articulado de poder emanado dos agentes-atores. Tais agentes possuem uma articulação mais aproximada com escalas de decisão de governo, as quais, no nível estadual, estão o governo do estado do Pará, por meio de sua Secretaria de Turismo (Setur-PA). Essa articulação permite aos agentes políticos do governo local de Marabá terem a oportunidade de atuarem nas questões que envolvem a política pública vinculada ao PMTB.

Uma das questões levantadas em reuniões dos agentes de turismo de Marabá tratava - implicitamente - da espacialidade do 'Mapa' na região Sul e Sudeste do Pará. A justificativa adotada é que se tornara improcedente efetivar uma política de turismo a partir da configuração regional apresentada pelo governo do estado, tal como se mostra na figura 2. Em outras palavras, os agentes de decisão política do turismo, vincularam a não-efetividade da PMTB às distâncias entre os municípios integrantes. Ao ser questionado sobre as distâncias físicas e como elas se tornam empecilhos ao desenvolvimento das políticas de turismo na região onde Marabá é central, o secretário de turismo deste município se pronuncia da seguinte forma:

(...) nós temos uma particularidade de nossa realidade que, primeiro, eu considero logística. Eu tenho certeza que nós temos cidades aqui com uma riqueza de cultura [a exemplo de Cametá]. Cametá está dentro de nosso polo (...) ninguém chega em daqui [de Marabá]. Não chega! Só chega indo por Belém, e, ainda assim, com muita dificuldade. Ela é rica, por exemplo, em festa de folclore. Como é eu integro um cidadão de Marabá à Cametá? [Isso] não pode ser uma coisa de roteiro turístico porque eu não tenho como estruturar isso, não tem como levar uma pessoa lá. Nós não temos logística dentro do estado que atenda a tudo isso aqui. O turista quer praticidade. Ele até viaja. Por exemplo: você vai viajar cinco dias de barco para conhecer a Pororoca. Ele sabe que não tem jeito: ele vai viajar porque ele quer ver aquilo, mas eu não posso ter isso como um roteiro turístico (...) (sic) (Entrevista concedida em 20 novembro de 2019, grifos próprios).

A manifestação de contrariedade dita pelo Secretário Municipal de Turismo de Marabá é endossada pelo presidente do Sindicato dos Hotéis do mesmo município. Segundo ele:

(...)A gente faz nossas reivindicações para quem? Para nosso Secretário de Turismo. Uma de nossas reivindicações é que o nosso eixo de turismo seja dividido porque ele é muito grande (...). Não tem como você unir uma região tão grande com políticas regionais de turismo. Sempre que há uma oportunidade, a gente tenta fazer com que sejam subdivididos esses núcleos. (sic) (Entrevista concedida em 13 de julho de 2019).

Como se pode perceber, um dos problemas apontados por alguns dos principais agentes do turismo centra-se em extensão territorial, algo típico para os recortes municipais na região Norte do Brasil. Segundo eles, portanto, uma exequibilidade da política de turismo neste recorte regional só teria sentido por meio da proximidade geográfica, tal como preconiza a normativa disposta na resolução que oficializa o PMTB. Seria, nesse caso, tomar o conteúdo pela forma, antes mesmo de se saber das relações econômicas atinentes entre os diversos fragmentos espaciais destinados ao turismo na região Sul e Sudeste do Pará.

O resultado da pressão dos agentes junto ao Fórum Regional de Turismo desencadeou outra região já publicada no 'Mapa' de 2019, por meio da Portaria n. 164, de 14 de junho de 2019 (PARÁ, 2019). Tal dispositivo normativo altera consideravelmente o número de recortes regionais, os quais seguem um direcionamento feito a partir da relação entre o executivo e os agentes-atores do turismo no território paraense, de acordo com suas sub-regiões ou particularidades histórico-econômicas, bem como geográficas. As novas regiões são: Belém, Amazônia Atlântica Guamá, Capim, Amazônia Atlântica Caeté, Araguaia, Carajás, Tocantins, Lago de Tucuruí, Baixo Tapajós, Alto Tapajós, Rio Amazonas, Campos do Marajó e Xingu.

Um dos aspectos enfatizados na Portaria n. 164, de 14 de junho de 2019 é o foco no desenvolvimento regional por meio de um planejamento coordenado e participativo, em que a ideia de "semelhança de ocupação" deve ser um dos eixos formadores para a constituição do novo 'Mapa'. A figura 3 mostra tão somente - a expressão do desenho cartográfico produto de uma decisão normativa via poder executivo do estado do Pará:

$\begin{array}{llllll}\text { Caminhos de Geografia } & \text { Uberlândia-MG } & \text { v. 21, n. } 77 & \text { Out/2020 } & \text { p. 193-208 Página } 203\end{array}$


Figura 3 - Mapa da região turística de Carajás, 2019.
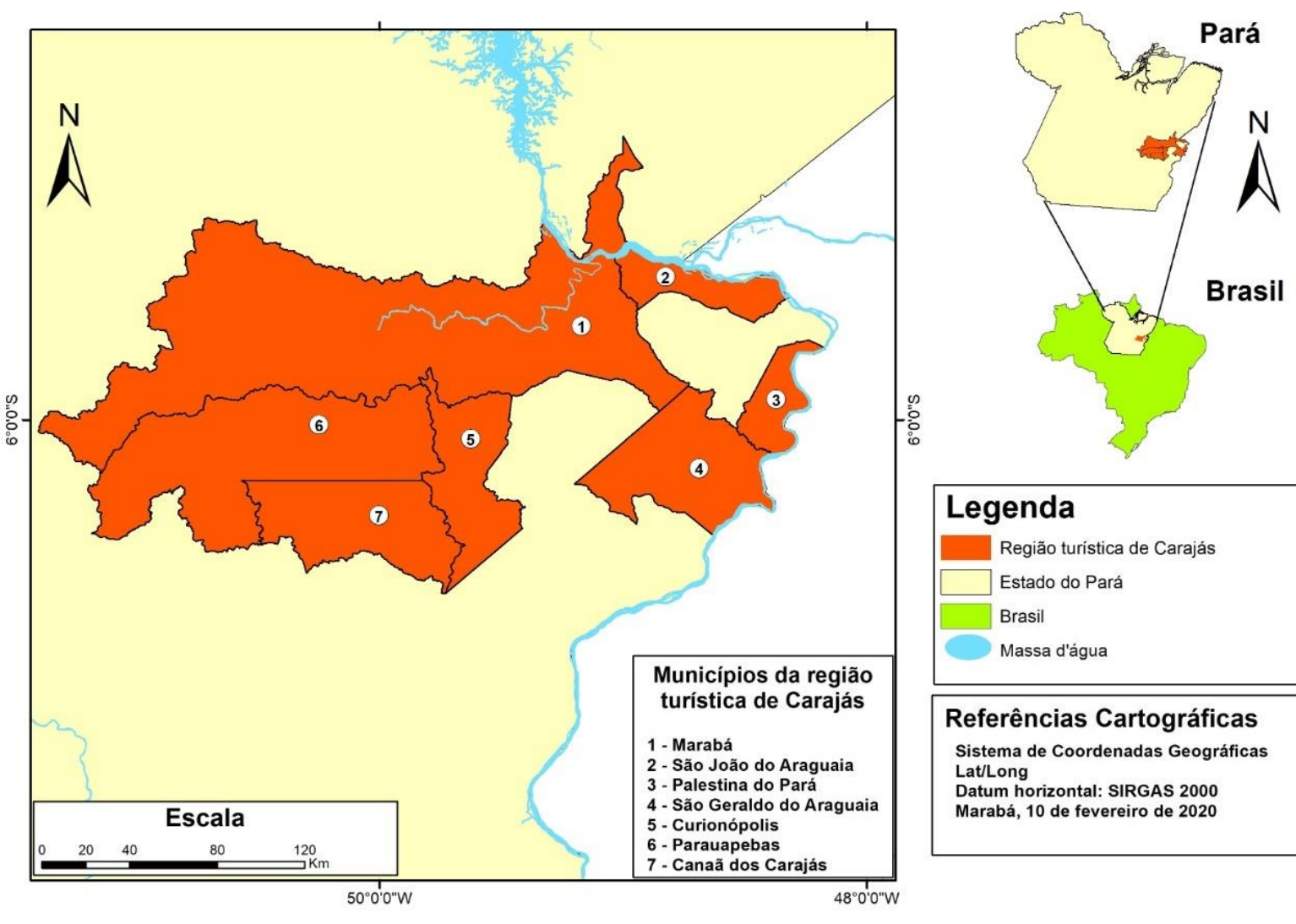

Fonte - IBGE (2015).

Marabá aparece no mapa anterior (figura 3) como o maior município em extensão territorial. O resultado dessa configuração, como fora dito anteriormente, é produto de uma pressão dos agentes de turismo de Marabá e dos municípios que integram esse novo 'desenho cartográfico'. Ainda que esse exemplo seja pequeno diante da diversidade regional do turismo presente em um país como o Brasil, essa constatação direciona a um amplo raciocínio da validade prática das normas do PMTB, bem como da geografia regional, quando não bem compreendida, pode inviabilizar uma política pública.

A observação feita anteriormente para a porção Sul e Sudeste do Pará leva a algumas análises importantes. Primeiramente, não se deve deixar de compreender que, mesmo não havendo clareza de um amplo conhecimento técnico-geográfico, os agentes do turismo mais influentes - aqueles que possuem afinidade com autoridades políticas tanto na capital do estado como no MTur- conseguem aplacar um raciocínio geográfico, ainda que não consigam dimensionar com profundidade a relação fluxos econômicos - extensão territorial. Nesse sentido, para eles, "o tamanho" da região pode ser decisivo na operacionalidade de um programa de governo, tal qual o PMTB. A articulação política entre os agentes, assim, é fundamental, ainda que isso não possa surtir efeitos práticos tão evidentes.

Em segundo lugar, o resultado da articulação entre os agentes reside em uma geografia regional na qual o 'Mapa' do turismo se configura como uma soma dos lugares e não em uma autêntica articulação das partes que formariam uma região por seus efeitos regionais. Esse ponto é crucial não apenas para se estabelecer uma crítica ao PMTB, mas para se compreender que tipo de geografia regional é desenvolvida no Brasil, ao se considerar a diversidade regional (macro, meso e microrregiões). $\mathrm{Na}$ região Norte, a articulação regional não encontra força suficiente ou é nula diante das regiões turísticas mais tradicionais no Brasil, o que leva a uma inconsistência na política federal para o turismo. Essa constatação leva a práticas tais como as verificadas nas falas dos representantes de turismo, os quais, diante do pouco ou nulo efeito regional que as localidades no Sul e Sudeste do Pará podem difundir, tomam o conteúdo pela forma. Ou seja, alegam que o 'tamanho' da região é um problema regional. Isso se torna mais claro ao se compreender o processo de criterização elaborado e publicado pelo governo federal, tal como se percebe na figura 4: 
Figura 4 - Mapa do estado do Pará segundo a categorização do Mapa do Turismo Brasileiro - Portaria n. 2005, de $9 / 12 / 2015$ do MTur.

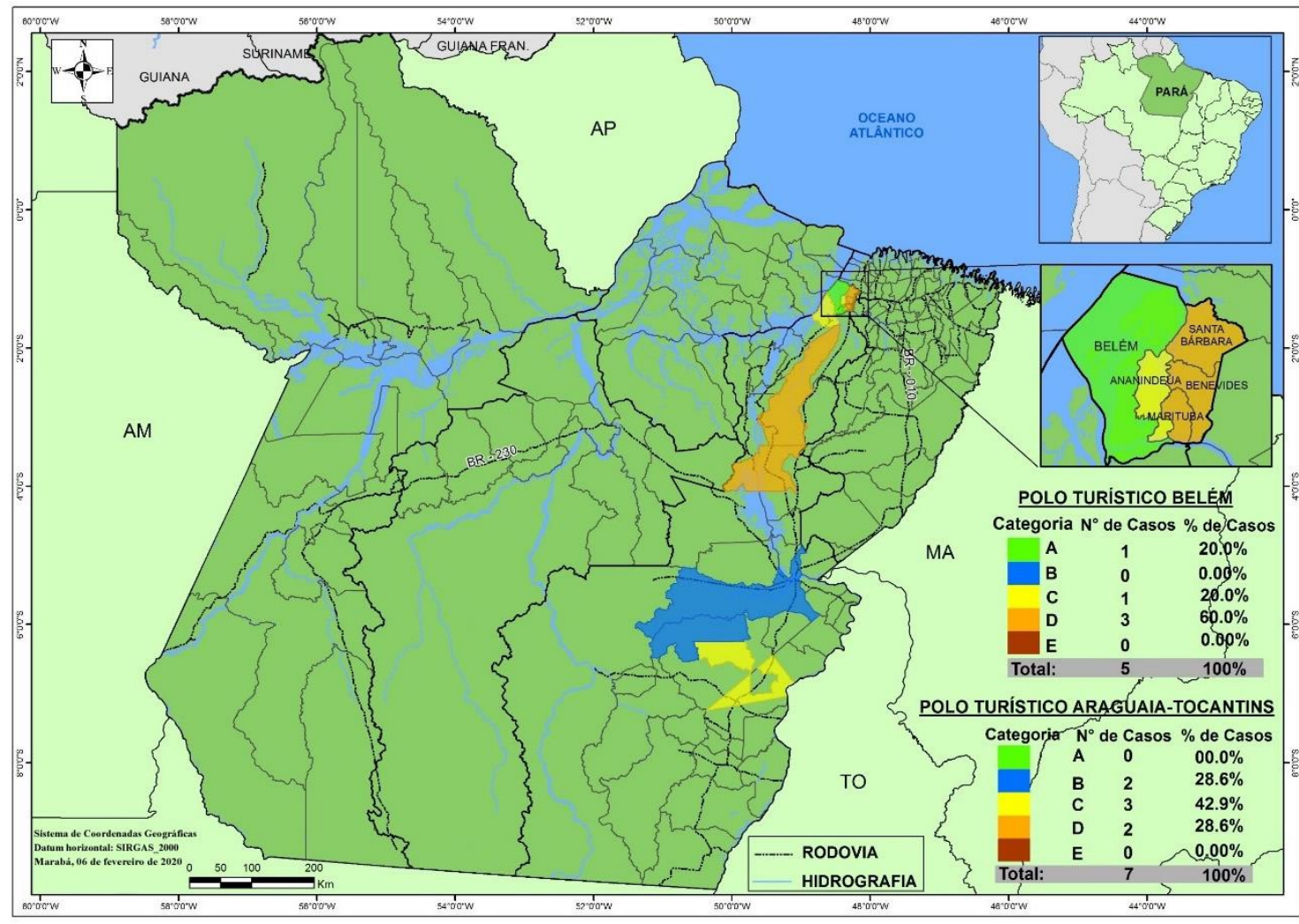

Fonte - IBGE, 2005; Mtur, 2015.

O município de Marabá (o mais extenso destacado em azul, integrante da região Araguaia-Tocantins), possui mais expressividade na região onde se localiza, em parceria com o município de Parauapebas (localizado ao sul de Marabá). Isso se deve pelo sistema de objetos presente nos dois municípios, com destaque para ambas as sedes municipais. Por seu turno, para os entrevistados anteriormente e, da mesma forma, ao se retomar o mapa da figura 2, a difusão regional não funcionaria na prática, daí a necessidade de haver uma fragmentação regional ao capricho das articulações políticas oriundas dos discursos dos agentes influenciadores, os quais se localizam em Marabá e Parauapebas. Há, de uma certa forma, uma regionalização mediada pelos discursos em detrimento do fenômeno da regionalização na prática, produto das forças econômicas diversas das regiões sul e sudeste do Pará.

$\mathrm{Na}$ análise das escalas espaciais do fenômeno turístico, a 'questão' amazônica pode ser comparada de acordo com o estudo feito por Cruz (2018) para o território brasileiro como um todo. Para esta autora, há um desenvolvimento desigual do turismo no Brasil devido à manifestação também desigual do capitalismo no território. Há que se entender esse aspecto a partir de um prisma histórico, pois, para aquela autora, o turismo de massa é resultado como também é condição do desenvolvimento desigual do modo de produção capitalista e ocorre de forma dialética no espaço.

A fim de comprovar como o desenvolvimento desigual se manifesta no território brasileiro a partir do turismo, Cruz (2018) apoia-se em dados concretos, dos quais, a chegada de estrangeiros no país antes da Copa do Mundo de Futebol respondia por 58,95\% somente nos estados de São Paulo e Rio de Janeiro, por exemplo. Além disso, a autora, reafirma a desigualdade no território ao se apoiar, também, em dados da Fundação Instituto de Pesquisas Econômicas - Fipe - a qual afirma que, entre 10 cidades brasileiras escolhidas pelos turistas, 8 são litorâneas.

A partir desse cenário, a proposta de Cruz (2018), tanto em seu aspecto teórico, quanto de método, torna-se factível. É nesse momento, portanto, que se pode comparar as geografias regionais entre um turismo de massa - consolidado no litoral brasileiro e nos grandes centros urbanos - com um turismo 
incipiente no interior da região - com mais rarefação espacial - como é o caso da Amazônia, nos termos de Santos e Silveira (2000). As escalas, os agentes e os processos do turismo são contingenciados por uma estrutura produtiva do turismo conforme o circuito das operações econômicas no território, portanto.

Nesse ponto, por fim, toma-se o pensamento de Frey (2000) quando dimensiona as forças políticas e suas relações de poder: "as disputas políticas e as relações das forças de poder sempre deixarão suas marcas nos programas e projetos desenvolvidos e implementados" (FREY, 2000, p. 219). Tais marcas podem ser visualizadas quando se trata de entender o funcionamento do PMTB na Amazônia, sobretudo, nas porções Sul e Sudeste do Pará.

\section{CONSIDERAÇÕES FINAIS}

O efeito que uma política pública tem na sociedade pode ser demasiadamente percebido ou estar inscrito nas entrelinhas de ideias, que estão, nestes moldes, cravadas no território. Não é à toa que este conceito possui uma volatilidade expressiva, pois, ao se tratar de território, as querelas emergem por motivos diversos e as escalas da ação se materializam na sociedade. Da mesma forma, não se pode perder de vista que a relação entre a política pública e a região possui artifícios produzidos no seio de conflitos sociais, os quais, o próprio território é condição para que uma 'regionalização de fato e uma regionalização de direito' aconteça. Limonad (2015), por exemplo, questiona por que há necessidade de uma regionalização.

Uma política de turismo que se projeta no território, tal como procede o PMTB, toma o território como receptáculo de ações e não como uma totalidade em plena mudança. Isso é mais visível ao se deparar com as incongruências que a política do PMTB faz surgir quando se pretende espacializar no território brasileiro de forma homogênea por meio de seus critérios. Ao se partir das convicções de Silveira (1999) para a dialética entre o global e local e suas reafirmações na região, percebe-se que a espacialidade regional do PMTB se torna mais inconsistente do que efetiva, o que pode gerar uma região por meio de um design sem seus conteúdos expressos pela multiplicidade de relações sociais interessadas na reprodução do turismo.

No que se refere à região Sul e Sudeste do Pará, da qual Marabá é município central, o desing anteriormente salientado é mais perceptível do que os efeitos que uma atividade turística pode provocar nesse recorte regional. Isso se mostrou evidente pelas falas dos entrevistados e pelos recortes cartográficos apresentados.

Há que se destacar dois temas provenientes do debate que o PMTB proporcionou à região Sul e Sudeste do Pará. O primeiro deles deve retomar as ideias de Brandão (2010) e, de outro lado, Escolar (1996). Para Brandão (2010), há a necessidade de se produzir uma ampla reflexão sobre o território a fim de posicionar o desenvolvimento em diferentes escalas, o que, obviamente, vai no contrafluxo de ideias como as do PMTB, que articulam a "região turística" de forma deficiente na Amazônia, sobretudo no Sul e Sudeste do Pará. Escolar (1996), por sua vez, é crítico à ideia do ressurgimento regional como se fosse algo que renovasse a análise regional. Para ele, seria mais interessante dar luz teórica e problematicamente ao caráter geopolítico do discurso, o que leva a uma investigação empírica mais completa.

A espacialidade do PMTB em Marabá, por fim, obedece aos critérios do governo federal sem atentar com propriedade - para a difusão regional que uma atividade turística pode vir a realizar. É a forma (da lei, da regra, da resolução, da concepção) se sobrepondo ao conteúdo (a vivacidade da região produzida material e imaterialmente pelos sujeitos).

\section{AGRADECIMENTOS}

À Fundação Amazônia de Amparo à Pesquisa do estado do Pará - Fapespa, por meio da Pró-reitoria de Pequisa e Inovação Tecnológica - Propit, pelo subsídio concedido por meio de bolsa de iniciação científica. Aos profissionais da cartografia: Profo Ms. Thiago Sabino, Prof ${ }^{a}$ Verena Leite e Prof. Dr. Estêvão Barbosa, pela elaboração dos mapas apresentados. 


\section{REFERÊNCIAS}

BARDIN, L. Análise do conteúdo. São Paulo: Edições 70, 1977 (Série Persona, 13).

BRANDÃO, C. Producción social del ambiente construído y sus escalas espaciales: notas para uma teoria acerca de las acciones y decisiones de sujetos concretos. In: FERNANDEZ, V.; BRANDÃO, C. (Orgs.). Escalas y políticas del desarrollo regional. Buenos Aires: Miño y Dávila, 2010, p. 241-272.

. Estratégias de desenvolvimento regional, decisões e interinstitucionalidades: desafios da abordagem crítica das transformações socioespaciais e os impasses para a efetivação das políticas regionais do Brasil. In: RANDOLPH, R.; SIQUEIRA, H.; OLIVEIRA, A. Planejamento, políticas e experiências do desenvolvimento regional: problemáticas e desafios. Rio de Janeiro: Letra capital/ Faperj, 2014, p. 121-146.

BRASIL. Diretrizes do programa nacional de municipalização do turismo - PNMT: III versão. Brasília: Embratur/ Ministério da Indústria, do Comércio e do Turismo, 1997.

. Programa de desenvolvimento do ecoturismo na Amazônia Legal - Proecotur:

propostas de pré-investimentos. Brasília: Ministério do meio ambiente, dos recursos hídricos e da Amazônia Legal/ Secretaria de coordenação da Amazônia, 1998.

2003.

Plano nacional de turismo: diretrizes, metas e programas. Brasília: Ministério do Turismo,

. Lei n. 11.771, de 17 de setembro de 2008. Lex: Diário Oficial da União, Poder Executivo, Brasília, DF, 17 set 2008.

. Ministério do Turismo. Gabinete do Ministro. Portaria no 105, de 16 de maio de 2013. Institui o Programa de Regionalização do Turismo e dá providências. Diário Oficial da União, Brasília, DF, 17 de mai. 2013.

. Portaria n. 144, de 27 de Agosto de 2015. Estabelece a categorização dos municípios pertencentes às regiões turísticas do Mapa do Turismo Brasileiro, definido por meio da Portaria MTur oㅜ 313, de 3 de dezembro de 2013, e dá outras providências. Diário Oficial da União: Brasília-DF. Disponível em: <http://www.turismo.gov.br/legislacao>. Acesso em: 05/07/2020.

. Ministério do Turismo. Programa Mapa do Turismo Brasileiro. Brasília: MTur, 2019. Disponível em: <http://www.regionalizacao.turismo.gov.br>. Acesso em 10/02/2020.

CARDOSO JR., J. Desmonte do Estado no governo Bolsonaro: menos república, menos democracia e menos desenvolvimento. In: FUNDAÇÃO PERSEU ABRAMO. Brasil: incertezas e submissão? São Paulo: Fundação Perseu Abramo, 2019, p. 151-170.

CRUZ, R. Política de turismo e território. 2. ed. São Paulo: Contexto, 2001 (Coleção turismo).

Desenvolvimento desigual e turismo no Brasil. Confins, Paris, vol. 36, n. 36, p.1-15, 2018.

DIAS, R.; MATOS, F. Políticas públicas: princípios, propósitos e processos. São Paulo: Atlas, 2012.

ESCOLAR, M. Crítico do discurso geográfico. São Paulo: Hucitec, 1996.

FARIA, C.; KARAM, R.; SANTOS, A. Agentes-atores na produção de políticas públicas espaciais. In: STEINBERGER, M. (Org.). Território, agentes-atores e políticas públicas espaciais. Brasília: Ler editorial, 2017, p. 93-128.

FERNÁNDEZ, V. El desarollo regional repensado - más allá de la nueva oscuridad neoliberal. In: RANDOLPH, R.; SIQUEIRA, H.; OLIVEIRA, A. Planejamento, políticas e experiências do desenvolvimento regional: problemáticas e desafios. Rio de Janeiro: Letra capital/ Faperj, 2014, p. 57-99.

FREY, K. Políticas públicas: um debate conceitual e reflexões referentes à prática da análise de políticas no Brasil. In: Planejamento e políticas públicas. São Paulo: Ipea, n. 21, 2000, p. 211-259.

HAESBAERT, R. Regional-global: dilemas da região e da regionalização na geografia contemporânea. Rio de Janeiro: Bertrand Brasil, 2010.

HARVEY, D. O espaço como palavra-chave. Revista geographia, v. 14, n. 28, p. 8-39, 2012. https://doi.org/10.22409/GEOgraphia2012.1428.a13641 
IBGE. Malha municipal: Pará. Rio de Janeiro, 2015. Disponível em: <http://www.ibge.gov.br/geociencias/organizacao-do-território. Acesso em: 05/07/2020.

KLINK, J.; OLIVEIRA, V.; ZIMERMAN, A. Development regimes, state spaces and complexity. What changes in the production of urban and regional space in Brazil? In: RANDOLPH, Rainer; SIQUEIRA, Hipólita; OLIVEIRA, A. Planejamento, políticas e experiências do desenvolvimento regional: problemáticas e desafios. Rio de Janeiro: Letra capital/ Faperj, 2014, p. 100- 120.

LIMONAD, E. Brasil, século XXI, regionalizar para quê? Para quem? In: LIMONAD, E.; HAESBAERT, R.; MOREIRA, R. (Orgs.). Brasil século XXI, por uma nova regionalização? agentes, processos e escalas. 2. ed. Rio de Janeiro: Letra Capital, 2015, p. 54-66.

MELAZZO, E. Problematizando o conceito de políticas públicas: desafios à análise e à prática do planejamento e da gestão. Presidente Prudente-SP. Revista Tópos, v. 4, n. 2, 2010, p. 9-32.

PARÁ. Plano ver-o-Pará: relatório executivo. Belém: Setur, 2016.

Portaria n. 164, de 14 de junho de 2019. Dispõe sobre a regionalização do turismo no Estado do Pará e dá outras providências. Diário Oficial do Estado do Pará: Belém-PA, seção Secretaria de Estado de Turismo, p. 89, 14/06/2019.

RANDOLPH, R. Apresentação. In: STEINBERGER, M. (Org.). Território, agentes-atores e políticas públicas espaciais. Brasília: Ler editorial, 2017, p. 17-18.

SANTOS, M.; SILVEIRA, M. Brasil: território e sociedade no início do século XXI. Rio de Janeiro/ São Paulo: Record, 2000.

SANTOS, M. O espaço dividido: os dois circuitos da economia urbana dos países subdesenvolvidos. $2^{\underline{a}}$ ed. São Paulo: Edusp, 2004 (Coleção Milton Santos, 4).

Da totalidade ao lugar. São Paulo: Edusp, 2005 (Coleção Milton Santos, 7).

SECCHI, L. Políticas públicas: conceitos, esquemas de análise, casos práticos. 2. ed. São Paulo: Cengage Learning, 2013.

SILVEIRA, M. Um país, uma região, fim de século e modernidades na Argentina. São Paulo: Fapesp/Laboplan/USP, 1999.

SOUZA, M. Mudar a cidade: uma introdução crítica ao planejamento e à gestão urbanos. Rio de Janeiro: Bertrand Brasil, 2001.

STEINBERGER, M. Introdução. In: __ Território, estado e políticas públicas espaciais. (Org.). Brasília: Ler editoria, 2013, p. 21-30.

. A inseparabilidade entre Estado, políticas públicas e território. In: Território, estado e políticas públicas espaciais. (Org.). Brasília: Ler editoria, 2013, p. 31-64.

. Introdução: a participação de agentes-atores nos discursos não escritos de políticas públicas espaciais. In: . Território, agentes-atores e políticas públicas espaciais. Brasília: Ler editor, 2017, p. 19-26.

Recebido em: 14/02/2020

Aceito para publicação em: 06/07/2020 